\title{
Кластеризация марганца в ZnS: Mn, Mg, полученного методом высокотемпературного самораспространяющегося синтеза
}

\author{
(С) Ю.Ю. Бачериков ${ }^{1}$, И.П. Ворона ${ }^{1}$, О.Б. Охрименко ${ }^{1}$, В.П. Кладько ${ }^{1}$, А.Г. Жук ${ }^{1}$, С.М. Окулов ${ }^{1}$, \\ Ю.О. Полищук ${ }^{1}$, А.В. Гильчук ${ }^{2}$, Ю.М. Романенко ${ }^{2}$, В.В. Кидалов ${ }^{3}$ \\ ${ }^{1}$ Институт фризики полупроводников им. В.Е. Лашкарёва Национальной академии наук Украины, \\ 03028 Киев, Украина \\ ${ }^{2}$ Национальный технический университет „Киевский политехнический институт им. И. Сикорского“, \\ 03506 Киев, Украина \\ ${ }^{3}$ Бердянский государственный педагогический университет, \\ 71100 Бердянск, Украина \\ E-mail: yuyu@isp.kiev.ua
}

Поступила в Редакцию 12 ноября 2019 г.

В окончательной редакции 19 ноября 2019 г.

Принята к публикации 19 ноября 2019 г.

Порошок $\mathrm{ZnS}: \mathrm{Mn}, \mathrm{Mg}$ был получен методом самораспространяющегося высокотемпературного синтеза с одновременным введением примесей $\mathrm{Mn}$ и $\mathrm{Mg}$. Обнаружено, что одновременное введение примесей $\mathrm{Mn}$ и $\mathrm{Mg}$ приводит к неравномерному распределению марганца, который формирует области с меньшей и большей концентрацией $\mathrm{Mn}$. В последнем случае ионы марганца образуют парамагнитные кластеры. В то же время из-за механического напряжения и деформации решетки в синтезированном $\mathrm{ZnS}: \mathrm{Mn}, \mathrm{Mg}$ образовалось большое количество центров самоактивированной люминесценции. Дополнительный отжиг приводит к более равномерному распределению $\mathrm{Mn}$ в полученном люминофоре $\mathrm{ZnS}: \mathrm{Mn}, \mathrm{Mg}$, что сопровождается повышением интенсивности полосы фотолюминесценции марганца и гашением полосы самоактивированной люминесценции.

Ключевые слова: самораспространяющийся высокотемпературный синтез, $\mathrm{ZnS}: \mathrm{Mn}, \mathrm{Mg}$, фотолюминесценция, сканирующая электронная микроскопия, электронный парамагнитный резонанс, отжиг.

DOI: 10.21883/FTP.2020.03.49030.9313

\section{1. Введение}

Сульфид цинка занимает важное место среди полупроводниковых материалов. Это обусловлено рядом его отличительных свойств, таких как большая ширина запрещенной зоны, способность излучать в видимой области при самом разнообразном внешнем воздействии: механическом, оптическом, рентгено-, катодо-, электровозбуждении и др. Кроме того, его высокая чувствительность к этим воздействиям позволяет использовать $\mathrm{ZnS}$ в качестве сенсора $[1,2]$. Поэтому создание на основе сульфида цинка новых композитных структур может значительно расширить его функциональные возможности и использование в микроэлектронике. В частности, к таким структурам относятся композиты, состоящие из $\mathrm{ZnS}$ и обладающие магнитными свойствами наночастиц металлов. Одной из наиболее подходящих магнитных примесей в $\mathrm{ZnS}$ является марганец благодаря его высокой растворимости и диффузионной способности. Теоретическое исследование поведения атомных кластеров переходных металлов показало [3], что кластеры марганца должны обладать значительным магнитным моментом и проявлять ферромагнитные свойства. Позже это было экспериментально подтверждено для +кластеров марганца $\mathrm{Mn}_{n}$ малых размеров $(n=11-99)$ [4].

Следует отметить, что получение композитных наноструктур, которые включают металлические кластеры с ферромагнитными свойствами, является достаточно сложной задачей. Как правило, металлические кластеры получают ограниченным количеством методов, к которым можно отнести лазерное напыление, испарение и конденсацию металла или сплава в плазменном потоке с инжекцией связующего частицы вещества, получение кластерных пучков и т.д. [5-7]. Все эти методы являются достаточно технически сложными и дорогостоящими. Поэтому для получения композиционных наноструктур со сложной внутренней структурой необходимо проводить апробацию появившихся не так давно новых методов синтеза материалов, таких как самораспространяющийся высокотемпературный синтез (CBC) $[8,9]$. Преимушеством данного метода является его простота и низкая стоимость, что позволяет значительно удешевить получаемые материалы. К тому же варьирование режимов синтеза позволяет получать материалы с различной стехиометрией, разной структурой (вюрцит, сфалерит), размерами частиц и т.д. В качестве реагента, способствующего появлению металлических кластеров в сульфиде цинка, может быть использован $\mathrm{Mg}$ или его соли для активизации процессов десульфурации.

Кроме того, было обнаружено, что дополнительное легирование магнием улучшает электролюминесцентные характеристики тонкопленочных устройств на основе $\mathrm{ZnS}: \mathrm{Cu}$ и $\mathrm{ZnS}: \mathrm{Mn}$, а также приводит к увеличению 

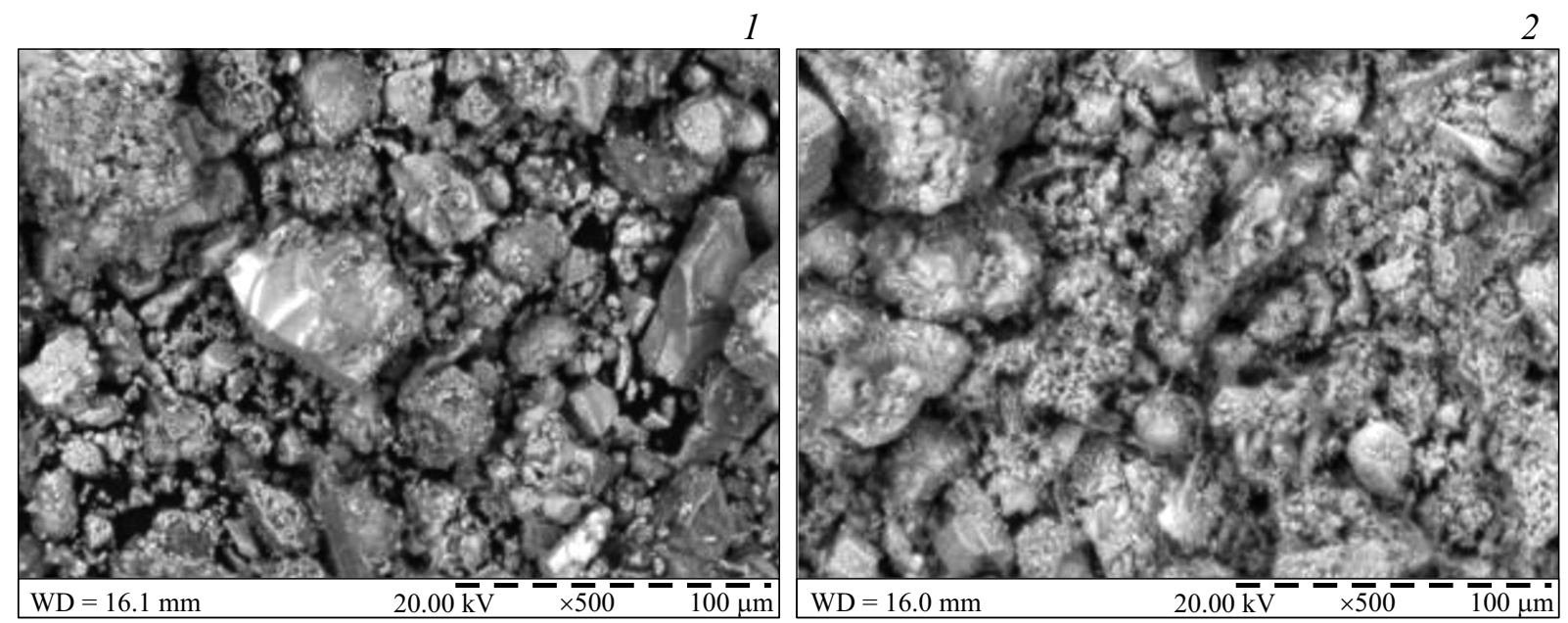

Рис. 1. СЭМ-изображения во вторичных электронах исходного (1) и отожженного при $800^{\circ} \mathrm{C}(2)$ порошка $\mathrm{ZnS}: \mathrm{Mn}, \mathrm{Mg}-\mathrm{CBC}$.

интенсивности фотолюминесценции (ФЛ) сульфида цинка $[10,11]$.

Получение высокоэффективного люминофора и фотопроводника с ярко выраженными ферромагнитными свойствами позволит существенно расширить функциональные возможности $\mathrm{ZnS}$, что и определяет актуальность данной работы. Цель работы заключалась в получении композитных материалов, состоящих из кластеров $\mathrm{Mn}$ в матрице $\mathrm{ZnS}$, в одном технологическом цикле методом самораспространяющегося высокотемпературного синтеза (СВС), и модификации данных кластеров при последующей термической обработке материала, а также в исследовании его люминесцентных и парамагнитных свойств до и после термического воздействия.

\section{2. Методика эксперимента}

Мелкодисперсный $\mathrm{ZnS}: \mathrm{Mn}$ был синтезирован методом СВС $[8,9]$. Легирование марганцем и магнием происходило непосредственно в процессе синтеза. Цинк и сера брались в стехиометрическом соотношении, а концентрации примесей $\mathrm{Mn}$ и $\mathrm{Mg}$ в шихте составляла $\sim 1.2$ и $5 \%$ по массе соответственно.

Отжиг $\mathrm{ZnS}: \mathrm{Mn}, \mathrm{Mg}$, полученного методом СВС (обозначаемый далее как $\mathrm{ZnS}: \mathrm{Mn}, \mathrm{Mg}-\mathrm{CBC}$ ), производился в лабораторной печи при температуре $800^{\circ} \mathrm{C}$ в течение 120 мин (охлаждение с печью). Для ограничения доступа атмосферы использовался газовый затвор из гранулированного активированного угля.

Спектры фотолюминесценции (ФЛ) и спектры возбуждения люминесценции (СВЛ) регистрировались при комнатной температуре на установке СДЛ-2. При регистрации СВЛ и ФЛ возбуждение люминесценции осуществлялось излучением ксеноновой лампы ДКСШ150, прошедшим через монохроматор МДР-12.

Анализ морфологии и локального элементного состава порошков осуществлялся методом растровой элек- тронной микроскопии на микроскопе PEM-106 (SELMI), оснащенном рентгеновским спектрометром с дисперсией по энергиям. Измерения проводили при ускоряющем напряжении 20 кВ.

Исследования рентгеновской дифракции проводились на рентгеновском дифрактометре Philips X'Pert$\mathrm{MRD}\left(\mathrm{Cu} K_{\alpha}\right.$, длина волны $\left.\lambda=0.15418 \mathrm{нм}\right)$ в геометрии Брегга-Брентано. Размер областей когерентного рассеяния $D_{h k l}(h k l$ - индексы Миллера отражающих плоскостей) определялся по формуле Шеррера $D_{h k l}=0.9 \lambda / \beta_{h k l} \cos \theta$, где $\lambda$ - длина волны излучения, $\beta_{h k l}$ - угловая ширина рефлекса на полувысоте, $\theta-$ угловое положение пика. Для более точного определения $\beta_{h k l}$ проводилась аппроксимация пиков функцией псевдоФойта (Pseudo-Voigt). Количественная оценка состава проводилась методом корундовых чисел.

ЭПР исследования проводились при комнатной температуре на спектрометре Х-диапазона Varian E-12.

\section{3. Результаты и обсуждение}

Исследование синтезированных и отожженных порошков $\mathrm{ZnS}: \mathrm{Mn}, \mathrm{Mg}-\mathrm{CBC}$ (см. рис. 1) методом сканирующей электронной микроскопии не показало явного изменения в размерах частиц порошков до и после отжига. Однако наиболее мелкая фаза после отжига является более сконгломерированной, что может быть обусловлено частичным спеканием порошка в процессе отжига.

Рентгенограммы исходного и отожженного порошков приведены на рис. 2. Их анализ показывает, что исходный порошок состоит в основном из гексагональной $(2 H)$ фазы сульфида цинка и металлического цинка. Количество $\mathrm{ZnS}$ и $\mathrm{Zn}$ [12] в смеси, оцененное методом корундовых чисел, составляет примерно 65 и 35\% соответственно. Кроме того, также в материале присутствует 


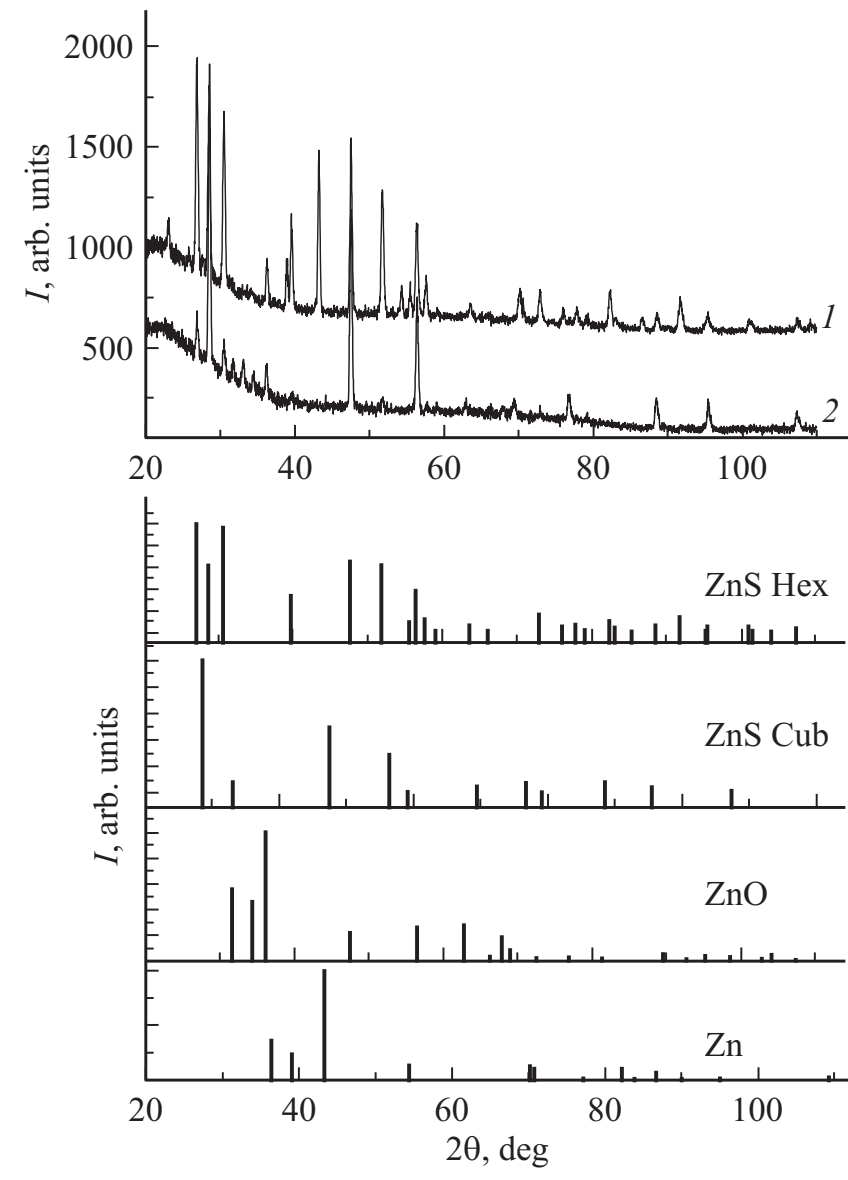

Рис. 2. Спектр рентгеновской дифракции порошка $\mathrm{ZnS}: \mathrm{Mn}, \mathrm{Mg}-\mathrm{CBC}$ до (1) и после (2)отжига. Внизу показаны стандартные рентгенограммы основных фаз в материале.

небольшое количество серы, о чем свидетельствует ряд слабых пиков в области $2 \theta \approx 23-28$.

Отжиг приводит к изменению фазового состава порошка. Как видно из рис. 2 , после отжига доминантной становится кубическая фаза $\mathrm{ZnS}$, но также присутствует и гексагональная фаза $\mathrm{ZnS}$. Их количество составляет 78 и $12 \%$ соответственно [12].

Кроме того, в порошке присутствует $\sim 10 \%$ оксида цинка $\mathrm{ZnO}$ [12]. Фазы металлического цинка, а также следов серы после отжига не наблюдается.

Изменение фазового состава порошкообразного $\mathrm{ZnS}$ при отжиге сопровождается изменением размера области когерентного рассеяния $(D)$. Значения этих величин оценены по формуле Шеррера [13] и представлены в табл. 1.

Элементные составы исходного и отожженного порошков, определенные методом рентгеноспектрального анализа с дисперсией по энергиям, приведены в табл. 2. Перед измерениями проводилась процедура калибровки с использованием эталонов. Погрешность измерений составляла для $\mathrm{Mg} \sim 30 \%, \mathrm{~S} \sim 2 \%, \mathrm{Cl} \sim 10 \%, \mathrm{Mn}$ $\sim 25 \%, \mathrm{Zn} \sim 2 \%$. Из результатов видно, что исходный порошок содержит почти поровну цинка и серы в атом- ном соотношении. Но, согласно результатам анализа фазового состава (табл. 1), значительная часть элементов не прореагировала. Во время отжига произошло активное испарение серы, что привело к относительному увеличению атомного содержания $\mathrm{Mn} \mathrm{и} \mathrm{Mg}$. Кроме того, металлический цинк частично прореагировал, а частично окислился с образованием $\mathrm{ZnO}$ (см. рис. 2).

Уменьшение атомного содержания серы с одновременным увеличением содержания $\mathrm{Mn}$ и $\mathrm{Mg}$ объясняется разными значениями удельной теплоты испарения $\Delta H$ соответствующих элементов. Для серы она составляет 10.5 кДж/моль, а для $\mathrm{Zn}, \mathrm{Mn}$ и $\mathrm{Mg}-114.8,221$ и 131.8 кДж/моль соответственно [14]. Интенсивность испарения пропорциональна $\exp (-\Delta H / k T)$. Таким образом, более чем десятикратная разница в значениях удельной теплоты испарения для серы и магния (марганца) при длительном отжиге приводит к активному испарению серы, за счет чего относительное содержание $\mathrm{Mg}$ и $\mathrm{Mn}$ возрастает.

На рис. 3, $а$ представлены спектры ФЛ порошкообразного $\mathrm{ZnS}: \mathrm{Mn}, \mathrm{Mg}-\mathrm{CBC}$ до (кривая 1) и после отжига при $800^{\circ} \mathrm{C}$ (кривая 2). Как видно из рис. 3 (кривая 1 ), спектр PL ZnS:Mn, Mg-CBC до отжига состоит из двух полос с $\lambda_{\max } \sim 460$ и $590 \mathrm{Hм}$, причем полоса с $\lambda_{\max } \sim 460$ нм является доминирующей. Последняя является суперпозицией нескольких полос, обусловленных центрами СА люминесценции [15]. Как правило, введение $\mathrm{Mn}$ в $\mathrm{ZnS}$ приводит к уменьшению интенсивности полос СА люминесценции и появлению широкой оранжевой полосы с максимумом при $\lambda_{\max } \sim 590$ нм $[16,17]$.

Полоса с $\lambda_{\max } \sim 460$ нм (кривая 1 , рис. $3, a$ ) состоит, как минимум, из трех индивидуальных полос с $\lambda_{\max } \sim 435,465$ и 515 нм. Полоса с $\lambda_{\max } 435$ нм может быть связана с наличием кислорода $[18,19]$ или хлоpa [20] в ZnS. Было показано [20], что полоса свече-

Таблица 1. Фазовый состав и область когерентного рассеивания $\mathrm{ZnS}: \mathrm{Mn}, \mathrm{Mg}-\mathrm{CBC}$ до и после отжига

\begin{tabular}{c|c|c|c|c}
\hline \multirow{2}{*}{ Фазы } & \multicolumn{2}{|c|}{ Исходный } & \multicolumn{2}{c}{ Отожженный } \\
\cline { 2 - 5 } & $\begin{array}{c}\text { Содержание } \\
\text { в объеме, \% }\end{array}$ & $D, \mathrm{~nm}$ & $\begin{array}{c}\text { Содержание } \\
\text { в объеме, \% }\end{array}$ & $D, \mathrm{~nm}$ \\
\hline $2 \mathrm{H}-\mathrm{ZnS}$ & 65 & 24.1 & 12 & 30.4 \\
$3 \mathrm{C}-\mathrm{ZnS}$ & - & - & 78 & 24.9 \\
$\mathrm{Zn}$ & 35 & 34.3 & - & - \\
$\mathrm{S}$ & $<1$ & & - & - \\
$\mathrm{ZnO}$ & - & - & 10 & 29.6
\end{tabular}

Таблица 2. Элементный состав исходного и отожженного $\mathrm{ZnS}: \mathrm{Mn}, \mathrm{Mg}-\mathrm{CBC}$.

\begin{tabular}{l|c|c|c|c|c}
\hline & $\mathrm{Zn}$, ат\% & $\mathrm{S}$, ат\% & $\mathrm{Mn}$, ат\% & $\mathrm{Mg}$, ат\% & $\mathrm{Cl}$, ат\% \\
\hline Исходный & 51.34 & 44.02 & 0.31 & 1.46 & 1.96 \\
Отожженный & 61.64 & 33.66 & 0.59 & 3.21 & 0.18
\end{tabular}



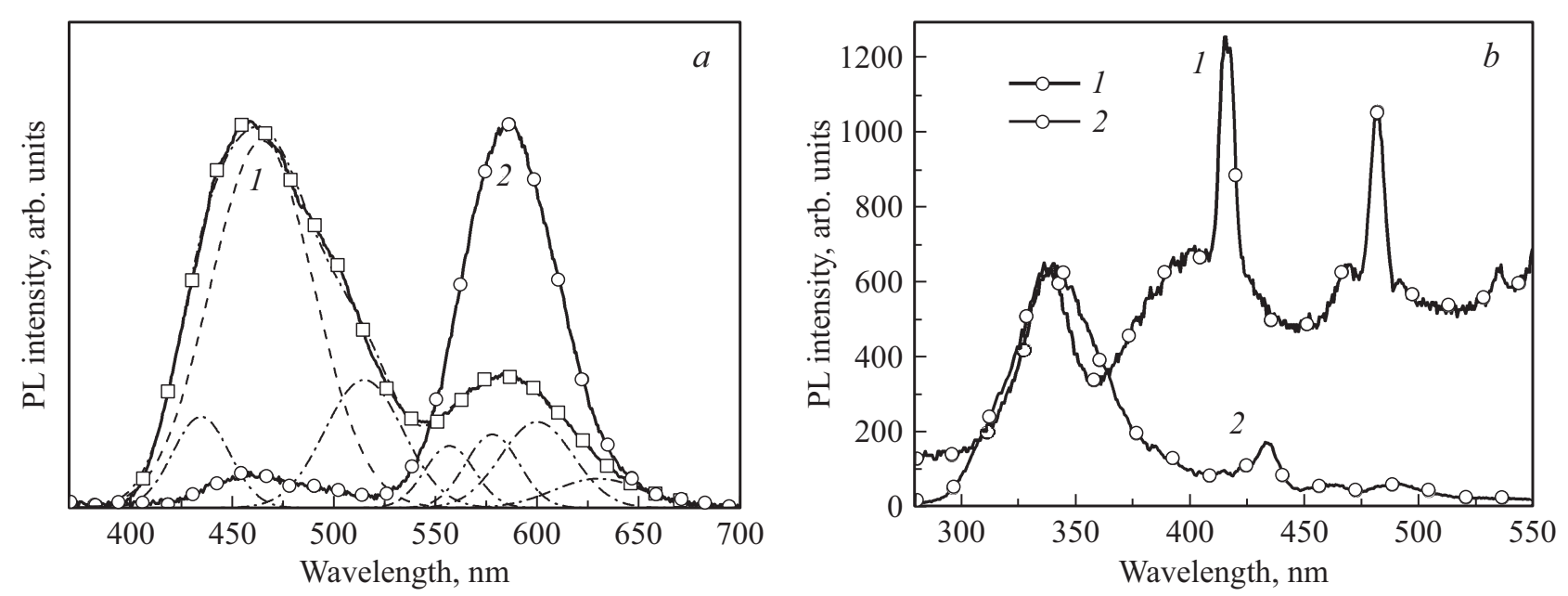

Рис. 3. Спектры ФЛ с $\lambda_{\text {exc }}=337$ нм $(a)$ и СВЛ полосы ФЛ с $\lambda_{\max }=580$ нм $(b)$ исходного $(1)$ и отожженного (2) порошка $\mathrm{ZnS}: \mathrm{Mn}, \mathrm{Mg}-\mathrm{CBC}$. Спектры ФЛ нормированы по их максимуму интенсивности. СВЛ нормированы по максимуму полосы фундаментального возбуждения.

ния с $\lambda_{\max } \sim 470$ нм, характерная для $\mathrm{ZnS}(\mathrm{Cl})$, является неэлементарной и состоит из полос с $\lambda_{\max }=496,466$, 426 и 405 нм. Согласно $[15,20]$, полосы с $\lambda_{\max }=496$, 466, 426, 405 нм связаны с центрами ассоциантом $V_{\mathrm{Zn}} \mathrm{Cl}_{\mathrm{S}},-\mathrm{Zn}_{i}, \mathrm{Cl}_{\mathrm{S}}$ и $V_{\mathrm{S}}$ соответственно. Полосу с $\lambda_{\max } \sim 515$ нм обычно связывают с избытком серы в кристаллах $\mathrm{ZnS}$ [21].

Полоса ФЛ с $\lambda_{\max } \sim 590$ нм является характерной для $\mathrm{ZnS}$, легированного Mn. Она также состоит из нескольких перекрывающихся отдельных полос с $\lambda_{\max } \sim 557,578,600$ и 630 нм. Согласно [22,23], полоса с $\lambda_{\max } \sim 600$ нм обусловлена излучательным переходом в ионах $\mathrm{Mn}^{2+}$, которые расположены в октаэдрических междоузлиях, а полоса с $\lambda_{\max } \sim 578$ нм связана с излучательным переходом в ионах $\mathrm{Mn}^{2+}$, расположенных вблизи дислокаций или точечных дефектов. Полоса ФЛ с $\lambda_{\max } \sim 630$ нм относится к $\mathrm{Mn}$ в фазе $\alpha$-MnS [24], которая не растворялась в решетке $\mathrm{ZnS}$ или с включениями фазы $\mathrm{MnS}$ при большом количестве $\mathrm{Mn}$ в сульфиде цинка. Полосу с $\lambda_{\max } \sim 557$ нм большинство авторов (см., например, $[25,26])$ ассоциируют с центрами, образованными ионами марганца, расположенными в подрешетке $\mathrm{Zn}$ в узлах вблизи локальных искажений и нарушений решетки.

Присутствие $\mathrm{Mg}$ в $\mathrm{ZnS}$, как видно из рис. 3, $a$, не влияет на спектральные характеристики ФЛ. Это согласуется с данными работ [27,28], где было показано, что введение $\mathrm{Mg}$ в $\mathrm{ZnS}$ приводит к значительному увеличению яркости ФЛ без изменения ее спектральных характеристик. Увеличение яркости излучения $\mathrm{ZnS}: \mathrm{Mg}$ обусловлено частичным заполнением тетраэдрических междоузлий и(или) замещением цинка ионами магния [18]. Это приводит к появлению механических напряжений в решетке $\mathrm{ZnS}$ и увеличивает количество собственных дефектов, в том числе тех, которые ответственны за СА люминесценцию.
Следует отметить, что форма спектров ФЛ $\mathrm{ZnS}: \mathrm{Mn}, \mathrm{Mg}-\mathrm{CBC}$ непосредственно после синтеза больше соответствует слабо легированному марганцем сульфиду цинка с содержанием Mn менее нескольких десятых процента $[16,17]$. Как правило, если содержание марганца в $\mathrm{ZnS}$ составляет более $1 \%$, то доминирует полоса с максимумом в области $590 \mathrm{Hм}$, а полосы СА ФЛ слабо выражены или отсутствуют [17].

При одновременном введении $\mathrm{Mn}$ и $\mathrm{Mg}$ в процессе СВС следует учитывать конкуренцию марганца как с цинком, так и с магнием в процессе его вхождения в решетку сульфида цинка (в быстро меняющихся условиях синтеза и кристаллизации $\mathrm{ZnS}$ ). Этот случай близок к случаю нестехиометрического соотношения компонентов в шихте во время СВС-процесса, когда избыток цинка в шихте составляет $<10 \%$ [16]. Это вызвано процессами десульфурации, связанными с присутствием примеси магния. В случае введения магния, из-за его высокой реакционной способности $\mathrm{Mg}$ легко образует соединения с кислородом и серой, вытесняя менее активные $\mathrm{Zn}$ и $\mathrm{Mn}$. Кроме того, сульфид магния образуется при $500-600^{\circ} \mathrm{C}$, тогда как температура образования для $\mathrm{MnS}$ составляет $\sim 1000^{\circ} \mathrm{C}$. Более низкая температура образования $\mathrm{MgS}$ и способность $\mathrm{Mg}$ замещать менее реакционноспособные металлы в соединениях с серой могут привести к затрудненному введению Mn в решетку $\mathrm{ZnS}$ и способствовать выпадению его в виде металлической фазы, т. е. к образованию кластеров марганца. Это косвенно подтверждается низкой интенсивностью полосы ФЛ с $\lambda_{\max } \sim 590$ нм, а также данными ЭПР, приведенными далее.

Хорошо известно, что дополнительная обработка, такая как термический отжиг, способствует более равномерному распределению легирующих примесей в решетке хозяина. Как видно из рис. 3, отжиг $\mathrm{ZnS}: \mathrm{Mn}, \mathrm{Mg}-\mathrm{SHS}$ приводит к значительному перераспределению полос 

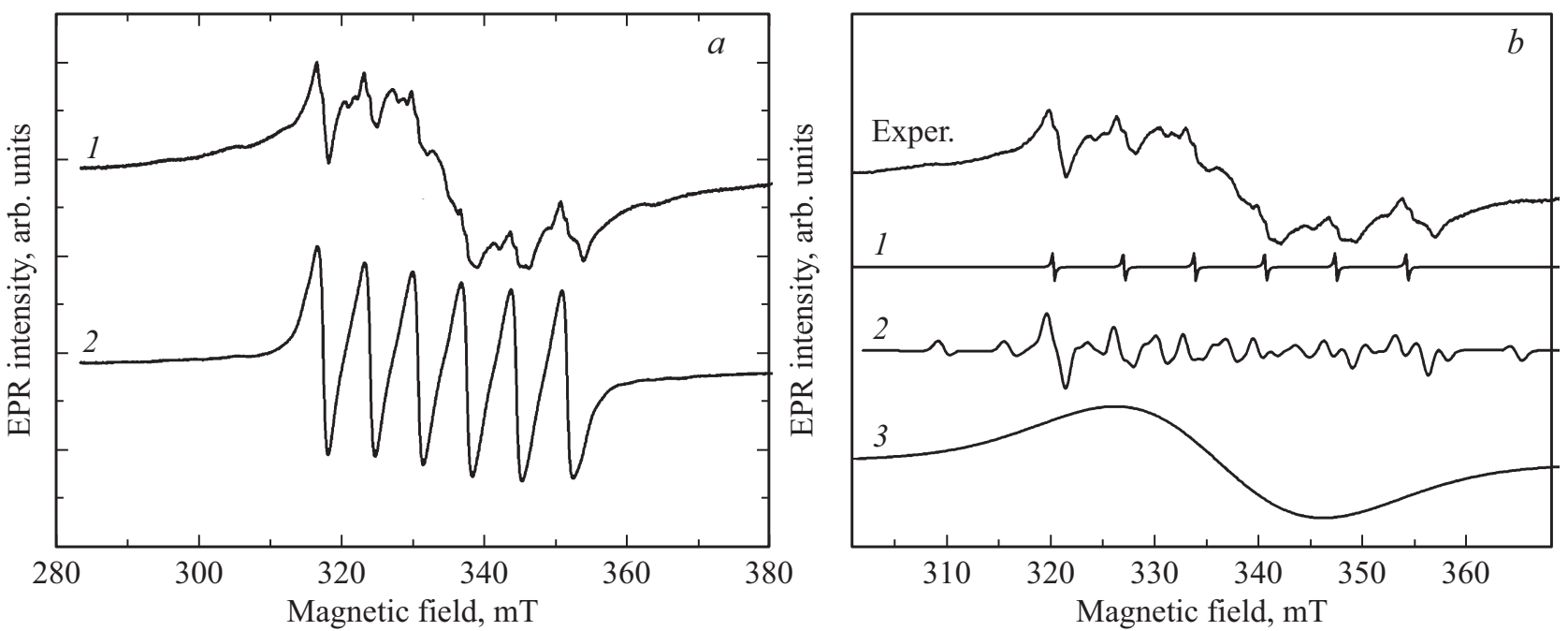

Рис. 4. $a$ - спектры ЭПР $\mathrm{ZnS}: \mathrm{Mn}, \mathrm{Mg}-\mathrm{CBC}$ до (1) и после отжига при $800^{\circ} \mathrm{C}(2) . b$ - разложение спектра исходного материала на компоненты: $1-\mathrm{Mn}_{\mathrm{Zn}}^{2+}$ в решетке кубического $\mathrm{ZnS}, 2-\mathrm{Mn}_{\mathrm{Zn}}^{2+}$ в решетке гексагонального $\mathrm{ZnS}, 3-\mathrm{Mn}^{2+}$, связанные сильным обменным взаимодействием (кластеры марганца).

ФЛ. После отжига полоса с максимумом до $\sim 590$ нм становится доминирующей в спектрах ФЛ. Эта полоса соответствует излучательному переходу в ионах $\mathrm{Mn}^{2+}$. В то же время интенсивность полосы СА ФЛ уменьшилась в 15 раз относительно полосы, связанной с $\mathrm{Mn}$.

CВЛ ZnS: Mn, Mg-SHS, синтезированные и отожженные при $800^{\circ} \mathrm{C}$, нормированные по максимуму полосы зона-зонного возбуждения, представлены на рис. $3, b$ (кривые 1,2). СВЛ ZnS:Mn, Mg-SHS содержит полосу с $\lambda_{\max } 340$ нм, связанную с фундаментальным поглощением в $\mathrm{ZnS}$, а также полосы с $\lambda_{\max } \sim 419,435,468$ и 493 нм, соответствующие известным [29-31] марганцевым полосам СВЛ. Последние обусловлены внутрицентровым переходам ионов $\mathrm{Mn}^{2+}$ из основного состояния $A_{1}$ в возбужденные ${ }^{4} T_{1},{ }^{4} T_{2},{ }^{4} E_{1},{ }^{4} A_{1}[30,31]$. Как видно из рис. $3, b$ (кривая 1 ), связанные с $\mathrm{Mn}^{2+}$ полосы СВЛ слабо выражены и намного слабее полосы фундаментального поглощения, что указывает на низкую концентрацию $\mathrm{Mn}$, вошедшего в узлы ZnS. После отжига спектр существенно изменяется: полосы, обусловленные $\mathrm{Mn}^{2+}$, доминируют в СВЛ (кривая 2). Это свидетельствует об увеличении атомного содержания Мn в отожженном $\mathrm{ZnS}: \mathrm{Mn}, \mathrm{Mg}-\mathrm{CBC}$ и хорошо согласуется с данными ЭДС (см. табл. 2). Разное положение обусловленных Мn полос на кривых 1 и 2 связано с разной локализацией $\mathrm{Mn}$ в решетке сульфида цинка до и после отжига. Размытие края зоны $\mathrm{ZnS}$ на кривой 1 (рис. $3, b$ ) по сравнению с кривой 2 обусловлено более высокой концентрацией $\mathrm{Cl}$, так как присутствие $\mathrm{Cl}$ в $\mathrm{ZnS}$ приводит к появлению набора мелких уровней, расположенных у дна зоны проводимости [32].

Ha pис. 4 представлены спектры ЭПР $\mathrm{ZnS}: \mathrm{Mn}, \mathrm{Mg}-\mathrm{SHS}$ до и после отжига при $800^{\circ} \mathrm{C}$. Спектр ЭПР порошка $\mathrm{ZnS}: \mathrm{Mn}, \mathrm{Mg}$ до отжига представляет собой типичный спектр ЭПР ионов $\mathrm{Mn}^{2+}$ в сильно леги- рованных порошках $\mathrm{ZnS}$ : Mn, который имеет смешанный фазовый состав (см., например, [16]). Он содержит три компоненты, обусловленные ионами $\mathrm{Mn}^{2+}$ с различной локализацией в материале. Первая компонента (сигнал 1), имеющая минимальную интенсивность, представляет собой шесть линий правильной формы с равной интенсивностью. Она обусловлена ионами $\mathrm{Mn}^{2+}$, замещающими $\mathrm{Zn}$ (ионами $\mathrm{Mn}_{\mathrm{Zn}}^{2+}$ ) в кубической решетке $\mathrm{ZnS}$. Интересно отметить, что РСА не обнаружил кубическую фазу сульфида цинка в данном материале. Это может объясняться более высокой чувствительностью сигнала ЭПР $\mathrm{Mn}^{2+}$ к наличию кубической фазы в $\mathrm{ZnS}$ [33]. Вторая компонента (сигнал 2) - это сложный сигнал ЭПР, который состоит из шести более интенсивных линий с нерегулярной формой в центре спектра и рядом менее интенсивных линий между ними и по бокам. Этот сигнал характерен для ионов замещения $\mathrm{Mn}_{\mathrm{Zn}}^{2+}$ в гексагональной решетке $\mathrm{ZnS}$. Последняя, наиболее интенсивный компонент (сигнал 3) - приблизительно симметричная широкая одиночная линия. Она также обусловлена ионами $\mathrm{Mn}^{2+}$, но их местоположение является спорным. Обычно ее приписывают ионам, расположенным в сильно дефектной области или области с высокой локальной концентрацией ионов марганца, связанных диполь-дипольным или обменным взаимодействием. Подобная линия ЭПР неоднократно наблюдалась и в других легированных марганцем материалах II-VI. В частности, в проведенных при разных температурах измерениях намагниченности и ЭПР в CdS:Mn было показано [34-36], что изменение интенсивности этой линии с температурой не подчиняется закону Кюри-Вейса. На основании этих исследований она была отнесена к кластерам марганца, связанным сильным обменным взаимодействием и демонстрирующим суперпарамагнитные свойства. Следует отметить, 
что подобные свойства (способность образовывать суперпарамагнитные кластеры) демонстрируют и другие примеси, в частности медь в сульфиде цинка $[37,38]$.

Наличие нескольких сигналов ЭПР указывает на неравномерное распределение марганца в синтезированном материале. Часть ионов марганца замещают ионы цинка в катионной подрешетке сульфида цинка, в то время как большинство ионов $\mathrm{Mn}^{2+}$ связаны сильным обменным взаимодействием и образуют суперпарамагнитные кластеры. Наличие таких кластеров может объяснить низкую интенсивность связанной с Мn люминесценции, так как большая часть марганца, образуя кластер, исключается из процессов излучательной рекомбинации.

Спектр ЭПР отожженного порошка представляет собой один сигнал, состоящий из шести линий с одинаковой интенсивностью. Очевидно, что он вызван ионами $\mathrm{Mn}_{\mathrm{Zn}}^{2+}$, но невозможно точно определить, в каком типе замещений (кубических или гексагональных) из-за уширения линий, вызванных диполь-дипольным взаимодействием ионов $\mathrm{Mn}^{2+}$. Появление этого уширения указывает на увеличение количества ионов $\mathrm{Mn}_{\mathrm{Zn}}$.

Таким образом, отжиг приводит к равномерному распределению марганца в материале за счет диффузии ионов $\mathrm{Mn}^{2+}$ из областей с их высокой локальной концентрацией, о чем свидетельствует исчезновение широкой полосы в спектре ЭПР отожженного порошка и значительное возрастание интенсивнолсти полос СВЛ, обусловленных $\mathrm{Mn}^{2+}$, по отношению к интенсивности полосы СВЛ, обусловленной зона-зонным переходом. Кроме того, высокотемпературный отжиг $\mathrm{ZnS}: \mathrm{Mn}, \mathrm{Mg}-\mathrm{SHS}$ способствует внедрению марганца в катионные узлы решетки $\mathrm{ZnS}$ (увеличение интенсивности и ширины линии соответствующего сигнала ЭПР).

Следует отметить, что отжиг порошкообразного $\mathrm{ZnS}: \mathrm{Mn}, \mathrm{Mg}-\mathrm{SHS}$ проводился при достаточно высокой температуре $800^{\circ} \mathrm{C}$ в течение 120 мин. Этот режим способствовал равномерному распределению атомов $\mathrm{Mn}$ в решетке $\mathrm{ZnS}$. В то же время выбор других режимов термообработки, возможно, приведет к видоизменению кластеров марганца и формированию кластеров с другими парамагнитными свойствами, однако это требует дополнительных исследований.

\section{4. Заключение}

Таким образом, использование $\mathrm{MgCl}_{2}$ в качестве солигатуры в процессе синтеза $\mathrm{ZnS}: \mathrm{Mn}$ методом СBC позволяет формировать металлические кластеры $\mathrm{Mn}$ c магнитными свойствами. Формирование кластеров марганца подтверждается появлением суперпарамагнитного сигнала ЭПР и объясняет слабую интенсивность связанных с Mn полос в спектрах ФЛ и СВС. Длительный температурный отжиг приводит к полному растворению металлических кластеров, к встраиванию Mn в решетку $\mathrm{ZnS}$ и увеличению концентрации ионов $\mathrm{Mn}_{\mathrm{Zn}}^{2+}$.
Это улучшает порошок как люминесцентный материал (возрастает интенсивность полосы ФЛ, связанной с Mn) и сопровождается изменением его фазового состава фаза $2 H-\mathrm{ZnS}$ доминирует в исходном материале, в то время как отожженный порошок содержит $12 \% 2 \mathrm{H}-\mathrm{ZnS}$ и $78 \% 3 C-\mathrm{ZnS}$.

\section{Конфликт интересов}

Авторы заявляют, что у них нет конфликта интересов.

\section{Список литературы}

[1] I.K. Sou, Z.H. Ma, Z.Q. Zhang, G.K.L. Wong. J. Cryst. Growth, 214-215, 1125 (2000).

[2] M.P. Sarma, J.M. Kalita, G. Wary. Mater. Sci. Semicond. Proc., 61, 131 (2017).

[3] S.K. Nayak, P. Jena. Chem. Phys. Lett., 289, 473 (1998).

[4] M.B. Knickelbein. Phys. Rev. Lett., 86 (23), 5255 (2001).

[5] R.L. Johnston. Atomic and Molecular Clusters (London, Taylor and Francis, 2002).

[6] J.S. Becker, H.J. Dietze. J. Anal. Chem., 359(4-5), 338 (1997).

[7] H. Pauly. Atom, Molecule, and Cluster Beams I:Basic Theory, Production and Detection of Thermal Energy Beams (Germany, Springer Verlag, 2000).

[8] V.S. Trofimov, E.V. Petrov. Int. J. Self-Propagating High-Temp. Synth., 23, 187 (2014).

[9] S.T. Aruna, A.S. Mukasyan. Curr. Opin. Solid-State Mater. Sci., 12, 44 (2008).

[10] S.H. Ryu, W.K. Kim, S.E. Lee. Trans. Electrical and Electron. Mater., 14 (1), 24 (2013).

[11] J. Yuan, D. Haneman, B. Gong. Mater. Res. Innovations, 2, 223 (1999).

[12] ICDD The International Centre for Diffraction Data $\mathbb{R}$ (ICDD®) www.icdd.com

[13] A.L. Patterson. Phys. Rev., 56, 978 (1939).

[14] G.W.C. Kaye, T.H. Laby. Tables of physical and chemical constants (by Longman in London, N.Y., 1986).

[15] М. Авен, Д.С. Пренер. Физика и химия соединений $A^{2} B^{6}$, под ред. С.А. Медведева (М., Мир, 1970). [Пер. с англ.: Physics and chemistry of II-VI Compounds, ed. by M. Aven, J.S. Prener (N.Y., North-Holland Publishing company Amsterdam, 1967)].

[16] Yu.Yu. Bacherikov, N.P. Baran, I.P. Vorona, A.V. Gilchuk, A.G. Zhuk, Yu.O. Polishchuk, S.R. Lavorik, V.P. Kladko, S.V. Kozitskii, E.F. Venger, N.E. Korsunska. J. Mater. Sci.: Mater. Electron., 28 (12), 8569 (2017).

[17] Yu.Yu. Bacherikov, I. Vorona, A. Zhuk, A.V. Gilchuk, N. Korsunska, I. Markevich. Semicond. Sci. Technol., 32, 1 (2017).

[18] Н.К. Морозова, И.А. Каретников, В.В. Блинов, Е.М. Гаврищук. ФТП, 35, 25 (2001).

[19] J. Díaz-Reyes, R.S. Castillo-Ojeda, R. Sanchez-Espíndola, M. Galvan-Arellano, O. Zaca-Moran. Curr. Appl. Phys., 15, 103 (2015).

[20] В.Ф. Туницкая, Т.Ф. Филина, Е.И. Панасюк, З.П. Илюхина. ЖПС, 14 (2), 239 (1971).

[21] Н.К. Морозова, И.А. Каретников, К.В. Голуб, Н.Д. Данилевич, В.М. Лисицын, В.И. Олешко. ФТП, 39 (5), 485 (2005). 
[22] Н.Д. Борисенко, М.Ф. Буланый, Ф.Ф. Коджеспиров, Б.А. Полежаев. ЖПС, 55, 452 (1991).

[23] М.Ф. Буланый, Б.А. Полежаев, Т.А. Прокофьев. ФТП, 32 (6), 673 (1998).

[24] N. Karar, F. Singh, B.R. Mehta. J. Appl. Phys., 95, 656 (2004).

[25] М.Ф. Буланый, Б.А. Полежаев, Т.А. Прокофьев, И.М. Черненко. ЖПС, 67, 208 (2000).

[26] W. Busse, H. Gumlish, R.O. Tornqvist. Phys. Status Solidi A, 76, 553 (1983).

[27] L.M. Dong, M.J. Li, X.D. Liu, K.J. Wu, Y.K. Guo. J. Ovonic Res., 12, 155 (2016).

[28] H. Joy Prabu, I. Johnson. Int. J. Engin. Res. Appl., 5, 99 (2015).

[29] D.A. Reddy, D.H. Kim, S.J. Rhee, B.W. Lee, C. Liu. Nanoscale Res. Lett., 9, 20 (2014).

[30] Т.А. Прокофьев, Б.А. Полежаев, А.В. Коваленко. ЖПС, $72(6), 788$ (2005).

[31] В.Ф. Агекян. ФТТ, 44 (11), 1921 (2002).

[32] Ю.Ю. Бачериков. ФТТ, 52 (8), 1539 (2010).

[33] V. Nosenko, I. Vorona, V. Grachev, S. Ishchenko, N. Baran, Yu. Bacherikov, A. Zhuk, Yu. Polishchuk, V. Kladko, A. Selishchev. Nanoscale Res. Lett., 11, 517 (2016).

[34] C. Barglik-Chory, C. Remenyi, C. Dem, M. Schmitt, W. Kiefer, C. Gould, C. Rüster, G. Schmidt, D.M. Hofmann, D. Pfisterer, G. Muler. Phys. Chem. Chem. Phys., 5, 1639 (2003).

[35] N. Feltin, L. Levy, D. Ingert, M.P. Pileni. J. Phys. Chem. B, 103, 4 (1999).

[36] G. Counio, S. Esnouf, T. Gacoin, J.-P. Boilot. J. Phys. Chem., 100, 20021 (1996).

[37] J.D. Bryan, D.R. Gamelin. Progr. Inorganic Chem., 54, 47 (2005).

[38] Yu.Yu. Bacherikov, I.P. Vorona, A.A. Konchits, S.V. Optasyuk, S.V. Kozitskiy, K.D. Kardashov. Functional Mater., 17, 158 (2010).

Редактор О.Г. Оганесян

\section{Manganese clasterization in ZnS : Mn, Mg synthesized by self-propagating high-temperature synthesis}

Yu.Yu. Bacherikov ${ }^{1}$, I.P. Vorona ${ }^{1}$, O.B. Okhrimenko ${ }^{1}$, V.P. Kladko ${ }^{1}$, A.G. Zhuk ${ }^{1}$, S.M. Okulov' ${ }^{1}$, Y.O. Polishchuk ${ }^{1}$, A.V. Gilchuk ${ }^{2}$, Yu.M. Romanenko ${ }^{2}$, V.V. Kidalov ${ }^{3}$

${ }^{1}$ Lashkaryov Institute of Semiconductor Physics, National Academy of Sciences of Ukraine, 03028 Kyiv, Ukraine

${ }^{2}$ National Technical University of Ukraine "Igor Sikorsky Kyiv Polytechnic Institute“, 03506 Kyiv, Ukraine

${ }^{3}$ Berdyansk State Pedagogical University, 71100 Berdyansk, Ukraine

Abstract $\mathrm{ZnS}: \mathrm{Mn}, \mathrm{Mg}$ powder was prepared by the selfpropagating high-temperature synthesis with the simultaneous introduction of an admixture of $\mathrm{Mn}$ and $\mathrm{Mg}$. The simultaneous introduction of $\mathrm{Mn}$ and $\mathrm{Mg}$ impurities during SHS was found to lead to non-uniform distribution of manganese forming areas with lower and higher concentrations of Mn. In the latter case manganese ions form paramagnetic clusters. At the same time, due to mechanical stress and lattice deformation in the synthesized $\mathrm{ZnS}: \mathrm{Mn}, \mathrm{Mg}$ a large number of self-activated luminescence centers were formed. Additional annealing leads to a more uniform $\mathrm{Mn}$ distribution in the resulting $\mathrm{ZnS}: \mathrm{Mn}, \mathrm{Mg}$ phosphor, which is accompanied by an increase in the intensity of the Mn-related photoluminescence band and quenching of the self-activated luminescence band. 